\title{
Stress-corrosion Cracking Susceptibility of Tungsten-inert-gas- welded TC4 Titanium Alloy Joints under Low Strain Rates
}

\author{
Yuwei Sun, ${ }^{1,2}$ Tao Feng, ${ }^{1 *}$ Yinzhen Wang, ${ }^{1}$ Qinglin Yang, ${ }^{1}$ and Zhen Jiao ${ }^{1}$ \\ ${ }^{1}$ College of Materials Science and Engineering, China University of Petroleum, Qingdao 266580, China \\ ${ }^{2}$ Safety Environment \& Technology Supervision Research Institute of Petrochina \\ Southwest Oil \& Gasfield Branch Company, Chengdu 610041, China
}

(Received September 30, 2018; accepted December 13, 2018)

Keywords: TC4 titanium alloy, welded joint, slow strain rate tensile tests, hydrogen embrittlement susceptibility

The microstructure of tungsten-inert-gas (TIG)-welded TC4 titanium alloy joints was analyzed. The stress-corrosion behavior and hydrogen embrittlement susceptibility of the welded joints were also studied by performing slow strain rate tensile tests (SSRTs) in 3.5\% $\mathrm{NaCl}$ solution. The results show that the heat-affected zone was mainly composed of $\alpha$, $\beta$, and $\alpha^{\prime}$ phases, in which the $\alpha^{\prime}$ phase comprised a coarse-grain region with a reticulated morphology. During tensile tests, the stress-corrosion sensitivity of the welded joints increased with increasing strain. The greatest stress-corrosion sensitivity occurred at a strain rate of 0.24 $\mathrm{mm} / \mathrm{min}$, where the joint fractured at the fusion line. Regarding the hydrogen embrittlement sensitivity, the fracture strength of the joints increased and the elongation percentage decreased with increasing polarization potential. In addition, the fracture surface was primarily composed of dimples, showing that the joints were not sensitive to hydrogen embrittlement.

\section{Introduction}

In the 21st century, ocean exploitation is attracting broad attention, and thus the development of marine science and technology is becoming more important. ${ }^{(1)}$ Because of the highly corrosive environment, all equipment used in ocean engineering must have specific properties including high specific strength, good toughness, and outstanding corrosion resistance to seawater.

Titanium and its alloys have many excellent characteristics such as good corrosion resistance, small elastic modulus, high fatigue performance, nonmagnetic and nontoxic properties, high weldability, wide applicability, and stable price. These mean that titanium and its alloys are commonly used as structural materials in ocean engineering. ${ }^{(2,3)}$ Among them, the TC4 titanium alloy is the most widely used. ${ }^{(3,4)}$ With the expanding range of applications of titanium alloys, their weldability and corresponding welding parameters are attracting more research interest. However, stress-corrosion cracking can easily occur inside welded components,

*Corresponding author: e-mail: ft_210750@163.com

https://doi.org/10.18494/SAM.2019.2157 
owing to the strength weakening of joints, the formation of a heterogeneous microstructure, high residual stress around the fusion zone, and weld defects inside the joints. ${ }^{(4,5)}$ The welding process of titanium alloys and their mechanical properties have been comprehensively studied, as well as their corrosion behavior. ${ }^{(6-9)}$ Nevertheless, the stress-corrosion cracking of welded joints has seldom been studied.

In this work, the stress-corrosion cracking behavior and hydrogen embrittlement susceptibility of 2-mm-thick tungsten-inert-gas (TIG)-welded TC4 joints are studied in a $3.5 \% \mathrm{NaCl}$ solution through slow strain rate tensile tests (SSRTs) with various strain rates. In addition, the fracture mechanism of the welded joints was analyzed by observing the fracture surface morphology. Our findings provide a good foundation for improving the corrosion resistance of TC4 titanium welded joints and evaluating their resistance to stress-corrosion cracking in the marine environment.

\section{Experimental Procedure}

The chemical composition of the as-received TC4 titanium alloy is shown in Table 1. The mechanical properties were also measured and shown in Table 2. As described in Table 3, different welding parameters were used to optimize the mechanical properties of the welded joints.

Then, the joint with the optimal mechanical properties was subjected to SSRTs. During the tests, the samples were immersed in $3.5 \% \mathrm{NaCl}$ solution, which was modified by $40 \%$ sulfuric acid to ensure a $\mathrm{pH}$ of $7-8$. Table 4 gives the strain rates in the SSRTs. For comparison, some samples were also tested in air. All the tests were conducted at a temperature of $300 \mathrm{~K}$ and a pressure of $1 \times 10^{5} \mathrm{~Pa}$. After sample fracture, an electron-probe microanalyzer (EPMA) was used to observe the fracture surface morphology.

Table 1

TC4 titanium alloy composition (mass fraction\%).

\begin{tabular}{cccccc}
\hline $\mathrm{Al}$ & $\mathrm{V}$ & $\mathrm{Fe}$ & $\mathrm{C}$ & $\mathrm{H}$ & $\mathrm{Ti}$ \\
\hline $5.5-6.8$ & $3.5-4.5$ & $\leq 0.30$ & $\leq 0.08$ & $\leq 0.015$ & bal \\
\hline
\end{tabular}

Table 2

Mechanical properties of TC4 titanium alloy.

\begin{tabular}{cccc}
\hline & $\sigma_{b}(\mathrm{MPa})$ & $\sigma_{0.2}(\mathrm{MPa})$ & $\delta(\%)$ \\
\hline Measured result & 1030 & 975 & 13.04
\end{tabular}

Table 3

Parameters of TC4 TIG welding.

\begin{tabular}{lccc}
\hline No. & $I(\mathrm{~A})$ & $v\left(\mathrm{~m} \cdot \mathrm{h}^{-1}\right)$ & Gas flow rate $\left(\mathrm{L} \cdot \mathrm{min}^{-1}\right)$ \\
\hline 1 & 100 & 15 & 8 \\
2 & 100 & 14 & 8 \\
3 & 100 & 13 & 8 \\
4 & 90 & 15 & 8 \\
5 & 90 & 14 & 8 \\
6 & 90 & 13 & 8 \\
7 & 80 & 15 & 8 \\
8 & 80 & 14 & 8 \\
9 & 80 & 13 & 8 \\
\hline
\end{tabular}


Table 4

Strain rates in test (unit: $\mathrm{mm} / \mathrm{min}$ ).

\begin{tabular}{lcccccc}
\hline & 1 & 2 & 3 & 4 & 5 & 6 \\
\hline Air & 0.012 & 0.018 & 0.024 & 0.12 & 0.18 & 0.24 \\
$3.5 \% \mathrm{NaCl}$ & 0.012 & 0.018 & 0.024 & 0.12 & 0.18 & 0.24 \\
\hline
\end{tabular}

Table 5

Tensile test results for TIG-welded joints.

\begin{tabular}{lccrrc}
\hline No. & $\sigma_{0.2}(\mathrm{MPa})$ & $\sigma_{b}(\mathrm{MPa})$ & $Z(\%)$ & $\delta(\%)$ & Fracture position \\
\hline 1 & 950 & 1020 & 6.07 & 4.92 & Fusion line \\
2 & 960 & 1040 & 24.49 & 11.40 & Base metal \\
3 & 975 & 1040 & 22.15 & 12.76 & Base metal \\
4 & 1010 & 1070 & 22.61 & 11.88 & Base metal \\
5 & 965 & 1020 & 4.53 & 5.28 & Fusion line \\
6 & 965 & 1030 & 16.50 & 11.22 & Base metal \\
7 & 985 & 1030 & 20.90 & 13.04 & Base metal \\
8 & 1010 & 1060 & 22.58 & 10.32 & Base metal \\
9 & 985 & 1030 & 23.47 & 13.24 & Base metal \\
\hline
\end{tabular}

To evaluate the stress-corrosion sensitivity of the welded joints in the $3.5 \% \mathrm{NaCl}$ solution, the parameter stress-corrosion index $I_{s c c}$ shown as Eq. (1) was introduced. A smaller calculated value (below 50 ) represents higher sensitivity to stress corrosion.

$$
I_{s c c}=\frac{\delta_{e}}{\delta_{c}} \times 100 \%
$$

Here, $\delta_{e}$ stands for percentage reduction of area in the $3.5 \% \mathrm{NaCl}$ solution and $\delta_{c}$ stands for percentage reduction of area in air.

\section{Results and Discussion}

\subsection{Mechanical properties of TIG-welded joints}

After TIG welding, tensile tests were performed on the welded joints for all the welding conditions. The measured mechanical properties are shown in Table 5. As shown in Table 5, the welded joints exhibited similar mechanical properties compared with the base metal once proper welding parameters were selected. In particular, joint No. 9 was chosen for further analysis because it showed the smallest difference from the base metal in terms of mechanical properties. Figure 1 shows the fracture surface of joint No. 9 after tensile tests. Pimples dominated the fracture surface of this ruptured joint, indicating the ductile fracture mode.

\subsection{Microstructure analysis of TIG-welded joints}

The metallographic structure of the TIG-welded joint is shown in Fig. 2, in which Fig. 2(b) gives a magnified view of the coarse-grain region observed in Fig. 2(a). As shown in Fig. 2, 


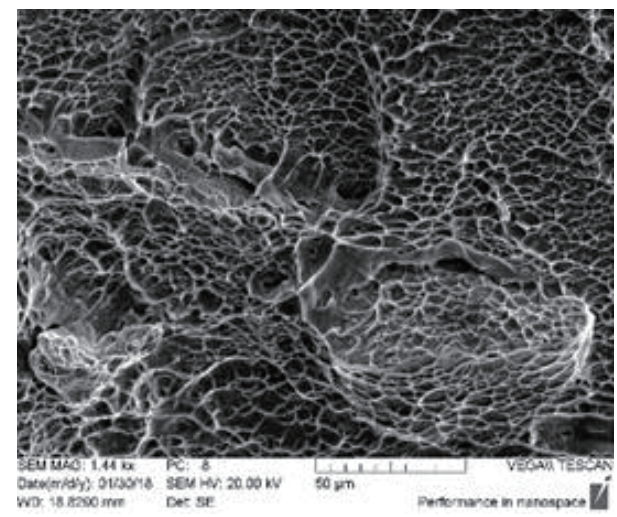

Fig. 1. Tensile fracture morphology of TC4 alloy TIG-welded joint.

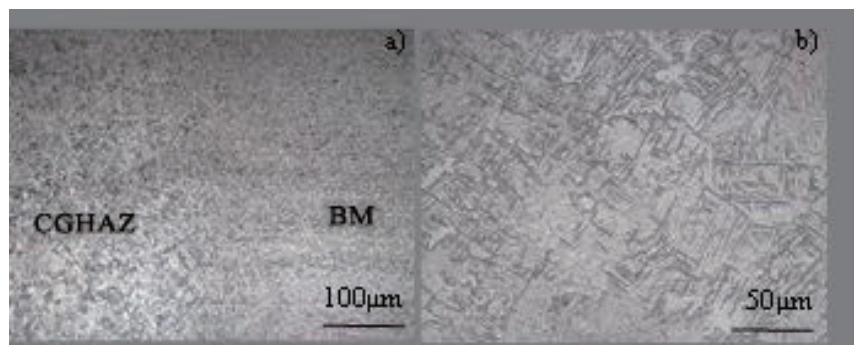

(a)

(b)

Fig. 2. Microstructure of TC4 alloy TIG-welded joint.

Table 6

Result of SSRTs in air and 3.5\% $\mathrm{NaCl}$ solution.

\begin{tabular}{|c|c|c|c|c|c|c|c|}
\hline Strain $\left(\mathrm{mm} \cdot \mathrm{min}^{-1}\right)$ & & 0.012 & 0.018 & 0.024 & 0.12 & 0.18 & 0.24 \\
\hline \multirow{2}{*}{$\sigma_{f}(\mathrm{MPa})$} & $3.5 \% \mathrm{NaCl}$ & 1445 & 1351 & 1441 & 1263 & 1231 & 1317 \\
\hline & Air & 1529 & 1498 & 1464 & 1328 & 1407 & 1438 \\
\hline \multirow{2}{*}{$Z(\%)$} & $3.5 \% \mathrm{NaCl}$ & 25.9 & 29.0 & 29.3 & 17.0 & 15.3 & 14.7 \\
\hline & Air & 29.5 & 29.5 & 30.1 & 21.4 & 23.8 & 23.6 \\
\hline \multirow{2}{*}{$\delta(\%)$} & $3.5 \% \mathrm{NaCl}$ & 16.37 & 16.02 & 14.83 & 14.66 & 14.20 & 13.32 \\
\hline & Air & 17.74 & 16.38 & 16.02 & 15.49 & 15.89 & 20.38 \\
\hline$I_{s c c}$ & 1 & 87.46 & 98.30 & 97.34 & 79.44 & 64.28 & 62.28 \\
\hline \multirow{2}{*}{ Fracture position } & $3.5 \% \mathrm{NaCl}$ & Base metal & Base metal & Base metal & Base metal & Base metal & Fusion line \\
\hline & Air & Base metal & Base metal & Base metal & Base metal & Base metal & Base metal \\
\hline
\end{tabular}

grains easily grew during welding in this region. Among them, the $\alpha$ phase became lamellar and coarse. Grain boundaries between the $\alpha$ phase and the $\beta$ phase became indistinct. As a result, these phases intermixed with each other and generated a complex reticulated morphology. The formation of these large grains can potentially deteriorate both the mechanical properties and corrosion resistance in this part.

\subsection{SSRT analysis of TIG-welded joints}

Table 6 shows the mechanical characteristics measured in the SSRTs of welded joints in air and $3.5 \% \mathrm{NaCl}$ solution.

As shown in Table 6, the fracture strength, percentage reduction of area, and percentage elongation of the welded joints decreased with increasing strain rate in both media. Moreover, the fracture strength, percentage reduction of area, and percentage elongation in the 3.5\% $\mathrm{NaCl}$ solution were smaller than that under the condition of air, given the same strain rates. Interestingly, the welded joint was insensitive to the stress corrosion and fracture occurring on the base metal side when the strain rate was smaller than $0.024 \mathrm{~mm} / \mathrm{min}$. Once the value reached $0.12 \mathrm{~mm} / \mathrm{min}$, the joint demonstrated high sensitivity to stress corrosion. Subsequently, the sensitivity monotonically increased with increasing strain rate. At the highest strain rate 
of $0.24 \mathrm{~mm} / \mathrm{min}$, the elongation was $20.383 \%$ in the $3.5 \% \mathrm{NaCl}$ solution and $13.324 \%$ in air. Meanwhile, the $I_{s c c}$ value decreased to $62.28 \%$ and the joint ruptured at the fusion line (as shown in Fig. 3).

The stress-strain curves obtained for samples in air and 3.5\% $\mathrm{NaCl}$ solution at different strain rates are shown in Fig. 4. In Fig. 4, both the elastic and plastic regions can be clearly

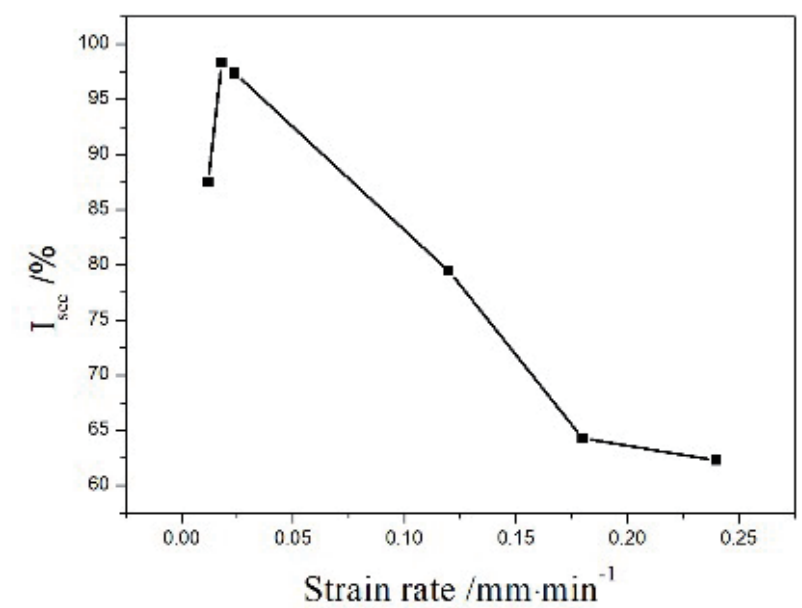

Fig. 3. Relationship between stress corrosion index and strain rate.

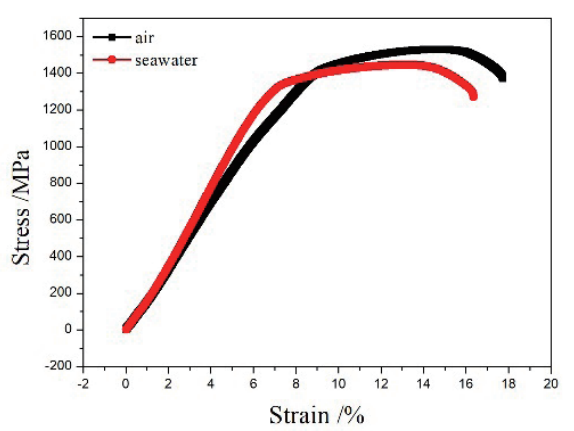

(a)

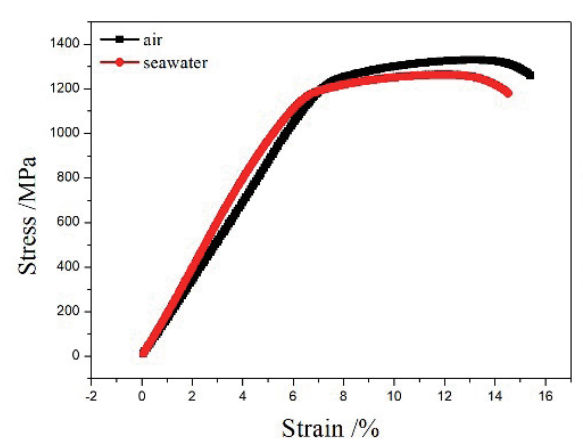

(d)

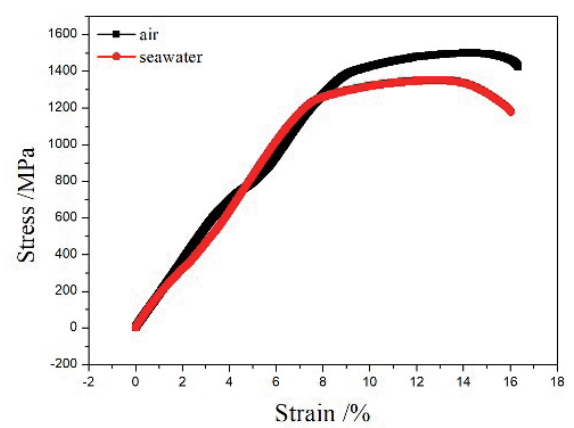

(b)

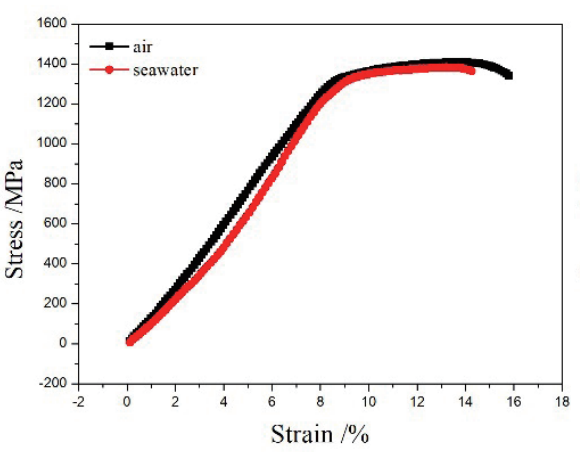

(e)

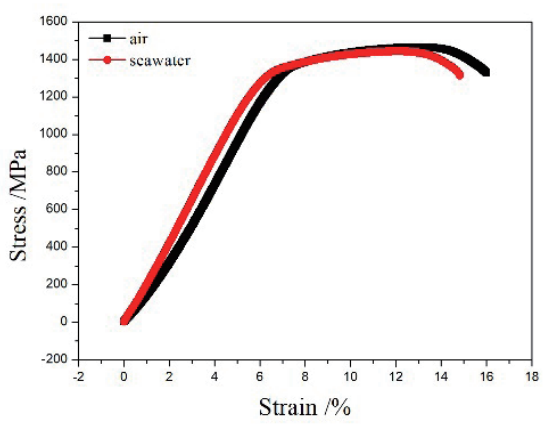

(c)

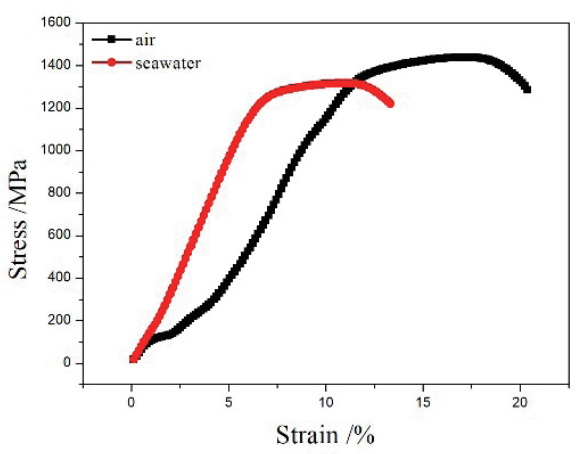

(f)

Fig.4. (Color online) Results of SSRTs for TC4-welded joints with different strain rates in air and $3.5 \% \mathrm{NaCl}$ solution. (a) 0.012 , (b) 0.018 , (c) 0.024 , (d) 0.12 , (e) 0.18 , and (f) $0.24 \mathrm{~mm} / \mathrm{min}$. 
distinguished, but material yield is indistinct. The decrease in the joint fracture strength in the $3.5 \% \mathrm{NaCl}$ solution indicated that the dislocations were able to easily move around under the condition of seawater. A driving force was required for dislocation motion owing to the decreased kinetic resistance. Under the condition of the $3.5 \% \mathrm{NaCl}$ solution, the fracture strength decreased with increasing strain rate, reaching $1317 \mathrm{MPa}$ at the highest strain rate of 0.24 $\mathrm{mm} / \mathrm{min}$.

The fracture surface morphology of the welded joints at strain rates of $0.018,0.18$, and 0.24 $\mathrm{mm} / \mathrm{min}$ is shown in Fig. 5. At the strain rate of $0.018 \mathrm{~mm} / \mathrm{min}$, a large number of dimples were distributed uniformly on the fractured surface, as is typical of the ductile fracture mode. At the strain rate of $0.18 \mathrm{~mm} / \mathrm{min}$, numerous dimples again were present on the fractured surface, with the dimples having a larger diameter than those observed at the strain rate of $0.018 \mathrm{~mm} / \mathrm{min}$. When the strain rate increased to $0.24 \mathrm{~mm} / \mathrm{min}$, the cleavage surface was observed on the fracture surface along with fewer dimples.

\subsection{Hydrogen embrittlement susceptibility}

Tests on the hydrogen embrittlement susceptibility of samples were conducted in the $3.5 \%$ $\mathrm{NaCl}$ solution, which had undergone electrochemical hydrogen charging for $2 \mathrm{~h}$, under a strain rate of $0.24 \mathrm{~mm} / \mathrm{min}$. The mechanical properties obtained from SSRTs at different polarization potentials are summarized in Table 7 and the associated stress-strain curves are shown in Fig. 6.

As shown in Table 7 and Fig. 6, the elongation of the welded joint was $16.12 \%$ at a polarization potential of $-0.484 \mathrm{~V}$ for the TC4 alloy, and it tended to decrease with increasingly

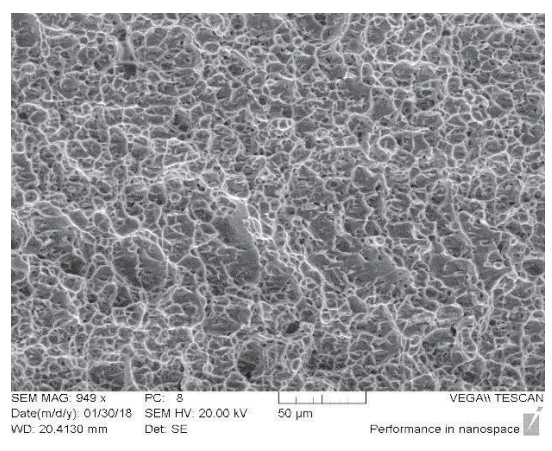

(a)

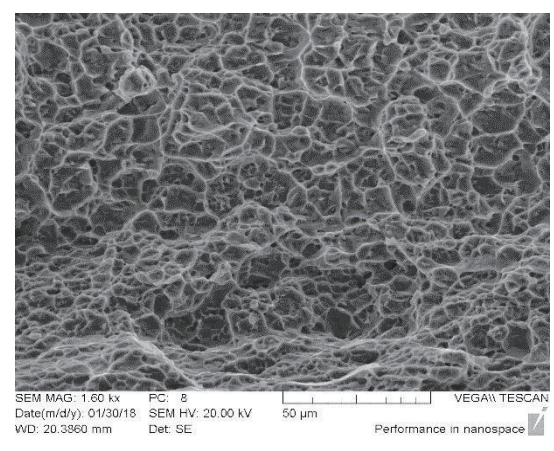

(b)

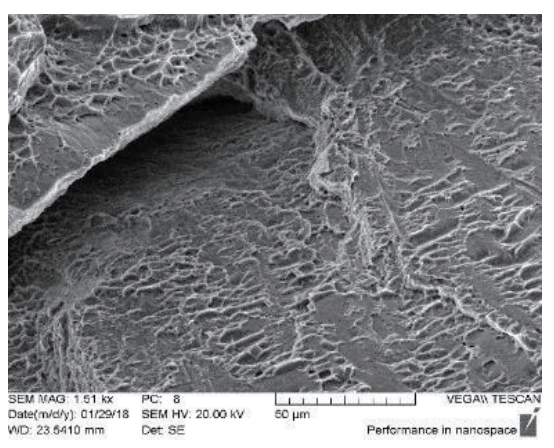

(c)

Fig. 5. Fracture morphology of TC4-welded joints in $3.5 \% \mathrm{NaCl}$ solution. (a) 0.018 , (b) 0.18 , and (c) $0.24 \mathrm{~mm} / \mathrm{min}$.

Table 7

Results of SSRTs for TC4 welded joints at different polarization potentials.

\begin{tabular}{lccccc}
\hline$U(\mathrm{~V})$ & -0.484 & -0.8 & -1.0 & -1.2 & -1.4 \\
$\sigma_{f}(\mathrm{MPa})$ & 1205 & 1305 & 1330 & 1332 & 1440 \\
$\delta(\%)$ & 16.12 & 15.99 & 14.27 & 13.59 & 13.32 \\
Fracture position & Fusion line & Base metal & Base metal & Base metal & Base metal \\
\hline
\end{tabular}




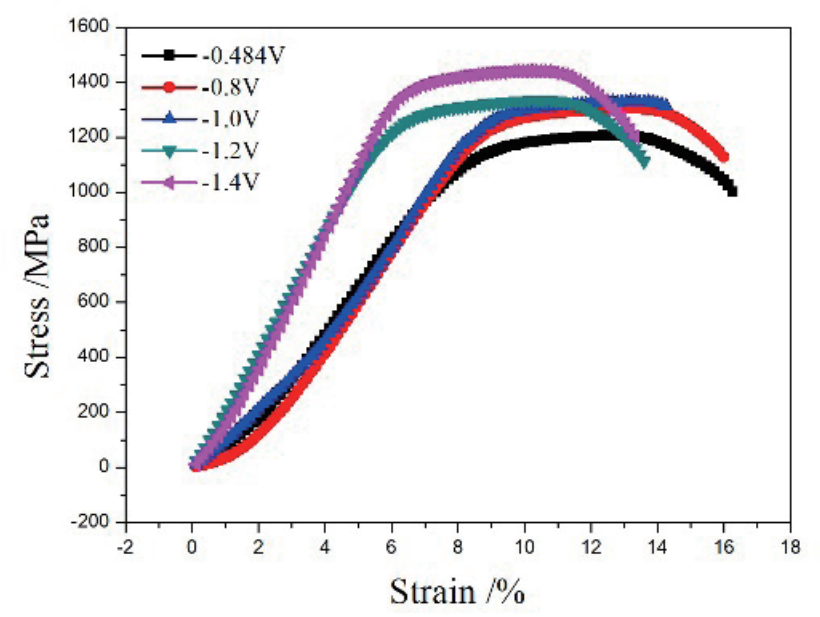

Fig.6. (Color online) Stress-strain curves of TC4 welded joints subjected to SSRTs under different polarization potentials.

negative polarization potential. The elongation reached a minimum of $13.32 \%$ at a polarization potential of $-1.4 \mathrm{~V}$. Furthermore, the fracture strength of the welded joint was $1205 \mathrm{MPa}$ at the self-corrosion potential. The fracture strength of the joint increased with increasingly negative polarization potential and reached $1440 \mathrm{MPa}$ at the polarization potential of $-1.4 \mathrm{~V}$.

TC4 titanium alloy is composed of an $\alpha$ phase and $\beta$ phase. Among them, the $\alpha$ phase is hexagonal close packed with a $0.291 \mathrm{r}$ Ti radius for the octahedral interstices, while the $\beta$ phase is body-centered cubic with a $0.291 \mathrm{r}$ Ti radius for the tetrahedral interstices. ${ }^{(10)}$ Therefore, the hydrogen saturability in the $\beta$ phase is larger than that in the $\alpha$ phase. For this $\alpha+\beta$-type alloy, solid-solution strengthening increased its tensile strength owing to the presence of the $\beta$ phase. Titanium reacts with hydrogen to form the hydride $\mathrm{TiH}_{x}$, which increases the hydrogen diffusion rate inside the $\beta$ phase. During the tensile tests, these hydrides may have entered crystal defects to constrain dislocation motion.

In this study, it has been found that the increased polarization potential due to hydrogen charging enhanced the fracture strength of the welded joint and decreased the elongation percentage. During the weld thermal cycle, the $\beta$ phase became less prevalent in the heataffected zone, and transformed into the $\alpha$ and $\alpha^{\prime}$ phases. In particular, there was little $\beta$ phase remaining in the fusion zone. Accordingly, the effect of solid-solution strengthening due to the presence of hydrogen was weakened in both the heat-affected and fusion zones.

Figure 7 shows the EPMA images of the fractured surface of welded joints at different polarization potentials. As shown in Fig. 7, at the self-corrosion potential, the morphology exhibited ductile-fracture characteristics. Even with the increase in polarization potential after electrochemical hydrogen charging, little difference was observed in the final fracture surface morphology, where dimples dominated. This indicates that electrochemical hydrogen charging had a negligible effect on the hydrogen embrittlement susceptibility of the welded joints. 


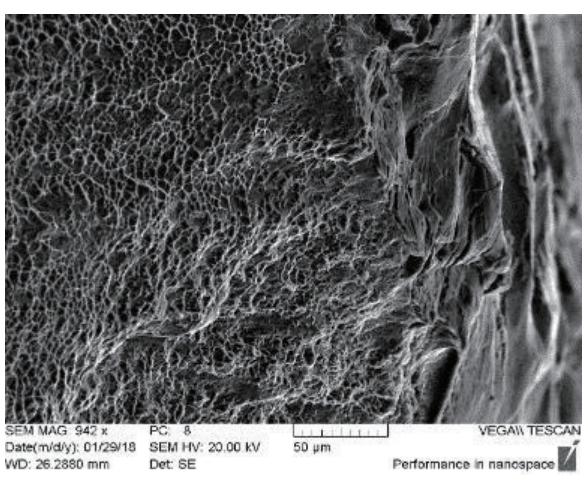

(a)

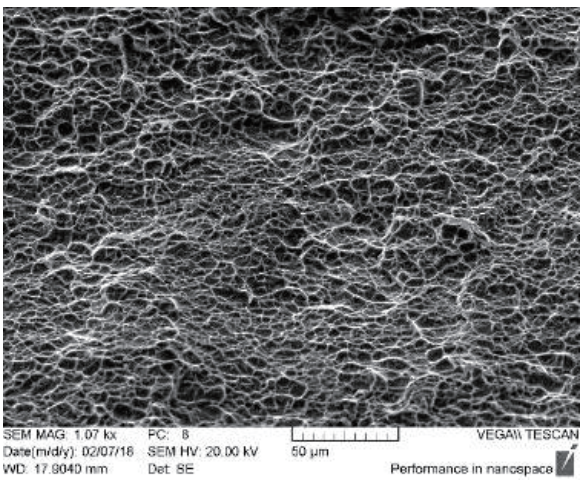

(c)

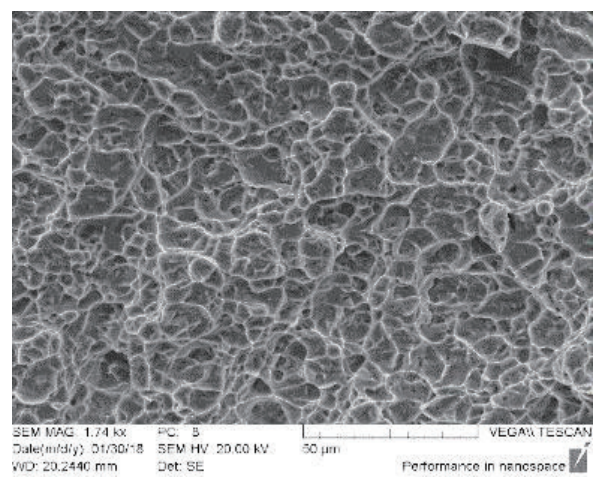

(b)

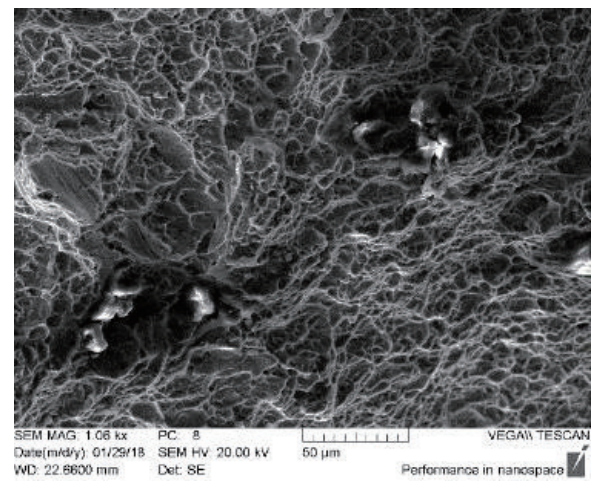

(d)

Fig. 7. Microfracture morphology of welded joints under different polarization potentials. (a) -0.484 , (b) -1.0 , (c) -1.2 , and (d) $-1.4 \mathrm{~V}$.

\section{Conclusions}

(1) A coarse-grain region was formed around the fusion line of the TIG-welded TC4 joints. This region was mainly composed of a lamellar $\alpha$ phase of short grains, resulting in the development of a complex reticulated structure. It was found that if the welding parameters were inappropriate, fracture occurred at the fusion line.

(2) The fracture strength, percentage reduction of area, and percentage elongation of the welded joint tended to decrease with increasing strain rate in both the $3.5 \% \mathrm{NaCl}$ solution and air. Under the same strain rate during SSRTs, the fracture strength, percentage reduction of area, and percentage elongation of the welded joints were smaller in air. At the strain rate of $0.24 \mathrm{~mm} / \mathrm{min}$, the stress-corrosion index achieved in the $3.5 \% \mathrm{NaCl}$ solution had the smallest value of $62.28 \%$, which represented stress-corrosion cracking susceptibility. Dimples were formed on the fracture surface at smaller strain rates, while the cleavage surface appeared after fracture at the strain rate of $0.24 \mathrm{~mm} / \mathrm{min}$.

(3) After electrochemical hydrogen charging, the fracture strength of the welded joint was enhanced and the elongation percentage decreased with increasing polarization potential. At the polarization potential of $-1.4 \mathrm{~V}$, the welded joints had the maximum fracture strength 
of $1440 \mathrm{MPa}$ and the minimum elongation of $13.32 \%$. Moreover, dimples dominated the fractured surface, indicating that the welded TC4 joint was not sensitive to hydrogen embrittlement.

\section{References}

1 T. Lukaczyk, T. Bieri, J. T. D. Sousa, and J. Levy: Oceans (IEEE, 2016). https://ieeexplore.ieee.org/ document $/ 7761485$

2 H. Ma, C. Du, Z. Liu, W. Hao, X. Li, and C. Liu: Acta Metall. Sinica 52 (2016) 331. http://www.ams.org.cn/CN $/ 10.11900 / 0412.1961 .2015 .00362$

3 H. Wang, B. Zhang, T. Wang, Y. Wen, and J. Feng: Trans. China Welding Inst. 5 (2015) 13. http://hjxb. cnjournals.net/ch/reader/view_abstract.aspx?flag=1\&file_no $=20150504 \&$ journal_id=hjxb

4 Y. Gong, S. Wang, J. Li, and Z. Zhang: Trans. China Welding Inst. 9 (2017) 91. http://hjxb.cnjournals.net/ch/ reader/view_abstract.aspx?flag $=1 \&$ file_no $=20170921 \&$ journal_id $=$ hjxb

5 F. Gao, Z. Liao, J. Xiong, and S. Li: Trans. China Welding Inst. 4 (2016) 124. http://hjxb.cnjournals.net/ch/ reader/view_abstract.aspx?flag $=1 \&$ file_no $=20160429 \&$ journal_id $=$ hjxb

6 J. Shi, H. Wang, L. Yang, and L. Liu: Trans. China Welding Inst. 2 (2017) 6. http://hjxb.cnjournals.net/ch/ reader/view_abstract.aspx?flag $=1 \&$ file_no $=20170214 \&$ journal_id $=$ hjxb

7 C. S. Barrett: Structure of Metals (Pergamon Press, Oxford, 2010) p. 982.

8 S. Liu, Y. Wang, and S. Sun: Rare Met. Mater. Eng. 8 (2017) 2240. http://www.rmme.ac.cn/rmme/ch/reader/ view_abstract.aspx?file_no $=20150403 \&$ flag $=1$

9 Z. Zhang, L. Dong, S. Guan, and R. Yang: Acta Metall. Sinica 53 (2017) 415. http://www.ams.org.cn/EN/ Y2017/V53/I4/415

10 B. Yuan, Y. Wang, Y. Zheng, and L. Gong: Rare Met. Mater. Eng. 6 (2017) 1486. http://www.rmme.ac.cn/ $\mathrm{rmme} / \mathrm{ch} / \mathrm{reader} / \mathrm{view}$ abstract.aspx?file_no $=20150378 \&$ flag $=1$ 